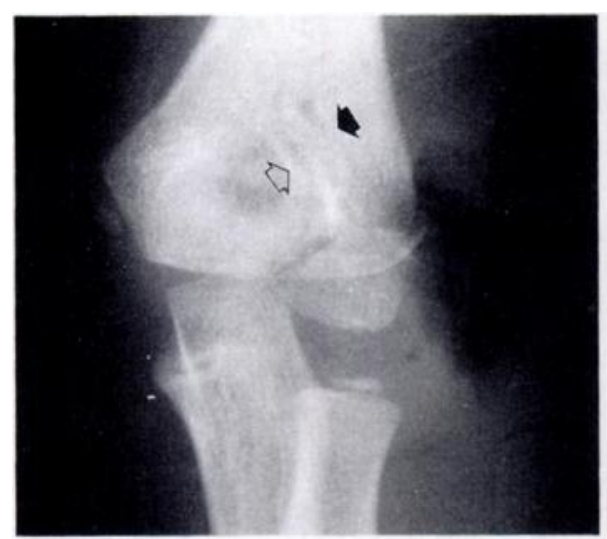

Fig. 1

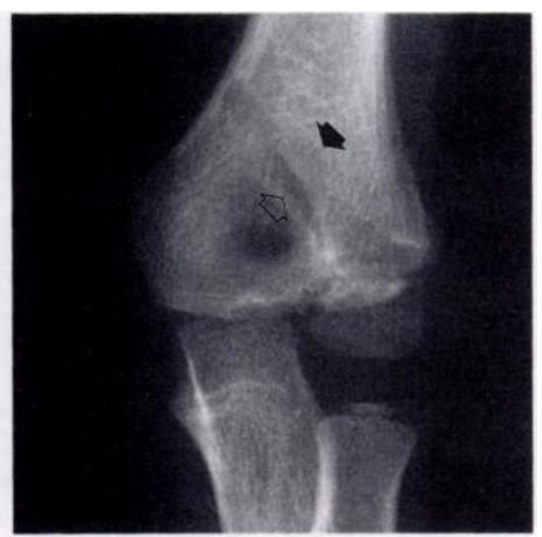

Fig. 2

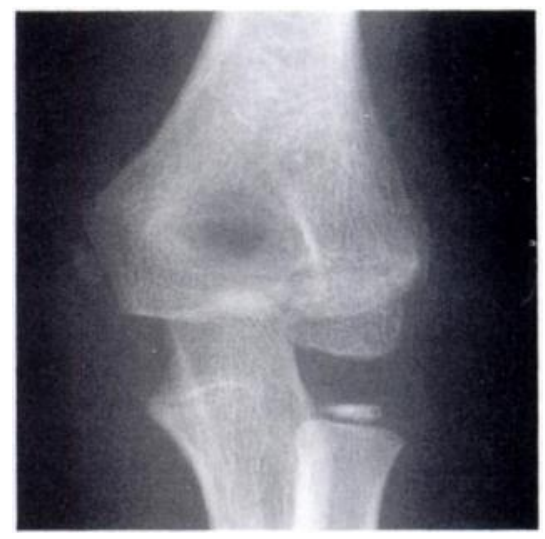

Fig. 3 healed spontaneously, also after a similar interval to that observed in adults. There was no apparent change in growth-plate function.

Osteolysis was seen, without a subcutaneous foreignbody reaction, in three $(14 \%)$ of the 21 fractures in children fixed by PGA pins, a lower frequency than in adults. Böstman (1991) suggested that perforation of both cortices may reduce the likelihood of foreign-body reaction and osteolysis, but both cortices were perforated in all three of our cases. Further study of the responses of human bone, growth plates and soft tissues to the degradation products of biodegradable implants is required.
No benefits in any form have been received or will be received from a commercial party related directly or indirectly to the subject of this article.

\section{REFERENCES}

Böstman OM. Osteolytic changes accompanying degradation of absorbable fracture fixation implants. J Bone Joint Surg [Br] 1991 : 73-B :679-82

Böstman O, Hirvensalo E, Vainionpää S, et al. Degradable polyglycolide rods for the internal fixation of displaced bimalleolar fractures. In Orthop 1990: 14:1-8.

Böstman O, Mäkelä EA, Törmä|ä P, Rokkanen P. Transphyseal fracture fixation using biodegradable pins. J Bone Joint Surg [Br] 1989; 71B:706.

Hope PG, Williamson DM, Coates CJ, Cole WG. Biodegradable pin fixation of elbow fractures in children: a randomised trial. $J$ Bone Joint Surg [Br] 1991 ; 73-B :965-8.

\title{
PATHOLOGICAL FRACTURE DUE TO RETAINED SURGICAL GAUZE
}

\author{
KAMAL AL ARABI, MIRZA BEG, HARRY SNOWDY, RICHARD WHITTAKER
}

There are many articles about the inadvertent retention of surgical swabs or gauze sponges, usually after laparotomy. We report an orthopaedic case in which the retained gauze caused a pseudotumour of the femur and resulted in a pathological fracture.

Case report. The patient sustained a closed fracture of the femur in 1977, treated in another country by open

K. Al Arabi, MD, FRCS, FRCS Ed, Head of Orthopaedics M. Beg, MD, FRCS G

King Fahd Hospital, PO Box 22490, Riyadh 11426, Saudi Arabia.

H. Snowdy, MD, MC, Colonel USAR

PO Box 2787, Augusta, Georgia 30904, USA.

R. Whittaker, MD, MC, Lt-Col USAR, Assistant Professor, University of Pennsylvania Medical School

Orthopaedic Specialists of Pottstown Ltd, Sunnybrook Medical Plaza, 1603 East High Street, Pottstown, Pennsylvania 19464, USA.

Correspondence to Dr R. Whittaker.

(C) 1992 British Editorial Society of Bone and Joint Surgery $0301-620 X / 92 / 6 R 58 \$ 2.00$

J Bone Joint Surg [Br] 1992; 74-B: 930-1. reduction and Küntscher nailing with one cerclage wire. The fracture healed and the rod was removed after a radiograph, taken in 1978, had shown unusual callus formation with a possible cyst (Fig. 1).

Thirteen years later, having had no adverse symptoms, the patient sustained a fracture of this femur during a minor twisting movement. Radiographs showed a pathological fracture through a severely eroded region with a medially displaced bony shell (Figs 2,3 ). This pseudotumour was larger than that shown in the 1978 radiograph. CT scans of the lesion showed no involvement of the soft tissues. The provisional diagnosis was chronic infection or a slow-growing benign tumour, but a biopsy revealed only inflammatory tissue with no growth on culture.

At an open operation, the fracture site was found to contain a mass of surgical gauze, $8 \mathrm{~cm}$ in diameter, with no sign of infection. Histological examination confirmed the presence of surgical gauze, and that there was no evidence of infection, tumour or osteomyelitis. The 


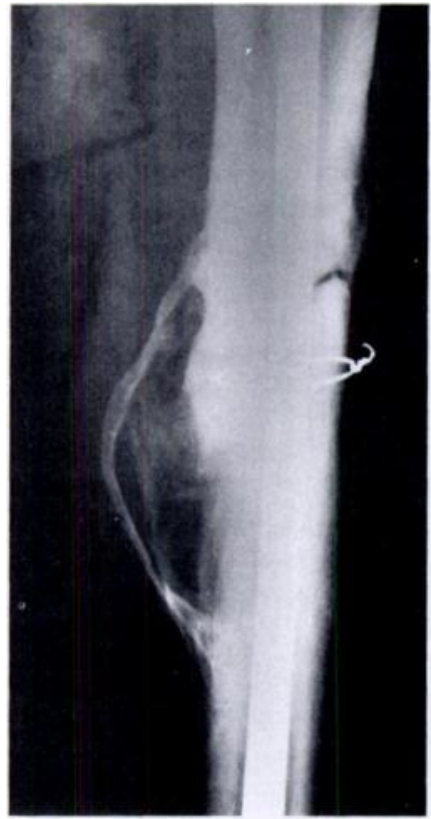

Fig. 1

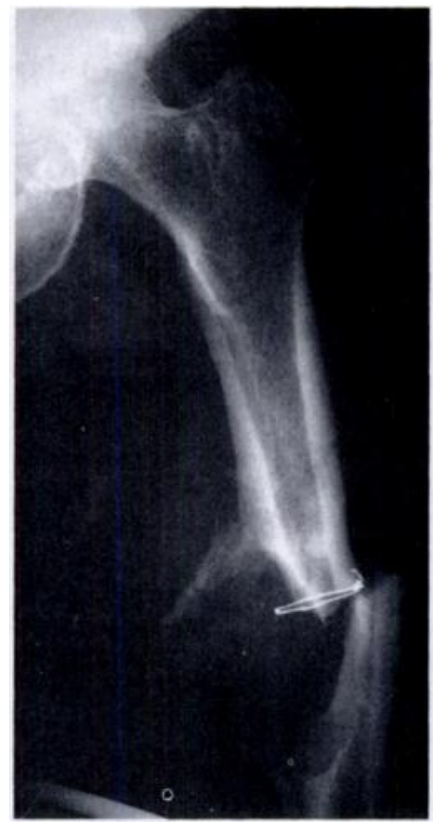

Fig. 2

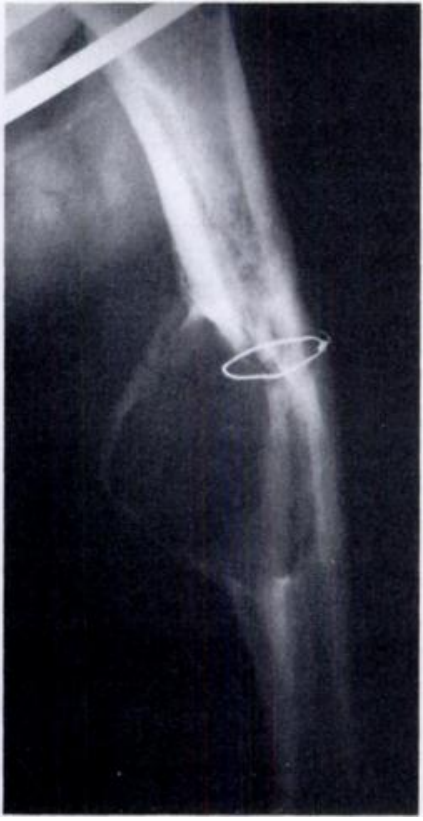

Fig. 3

Radiographs of the lesion: in 1978 (1), and in 1991, before (2) and after (3) closed reduction. The fracture was later nailed and grafted.

fracture was successfully treated by locked nailing and bone grafting.

Discussion. The pseudotumour and pathological fracture resulted from gradual bony erosion by the retained gauze sponges, and the cerclage wire may have contributed to the weakening of the bone. Rappaport and Haynes (1990) reported four patients with retained intra-abdominal surgical sponges, and emphasised that they may remain quiescent for many years, and then present as masses, while Serra et al (1988) coined the term "surgical gauze pseudotumour".

Our case emphasises the continued importance of careful swab or sponge counts, and of the use of easily recognised radio-opaque markers.

The authors wish to thank the following: Marilyn Chapis for the literature review, Elizabeth Rosengren for typing, and Paul Giaschi for the photographs.

No benefits in any form have been received or will be received from a commercial party related directly or indirectly to the subject of this article.

\section{REFERENCES}

Rappaport W, Haynes K. The retained surgical sponge following intraabdominal surgery. Arch Surg 1990; $125: 405-7$.

Serra J, Matias-Guiu X, Calabuig R, et al. Surgical gauze pseudotumor. Am J Surg 1988: $155: 235-7$. 